\title{
Correlations of kinetic parameters in biomass pyrolysis with solid residue yield and lignin content
}

\section{$\operatorname{AUTHOR}(\mathrm{S})$ :}

Hashimoto, Kenji; Hasegawa, Isao; Hayashi, Junichi; Mae, Kazuhiro

\section{CITATION:}

Hashimoto, Kenji ... [et al]. Correlations of kinetic parameters in biomass pyrolysis with solid residue yield and lignin content. Fuel 2011, 90(1): 104-112

\section{ISSUE DATE:}

2011-01

URL:

http://hdl.handle.net/2433/131857

\section{RIGHT:}

(C) 2010 Elsevier Ltd; This is not the published version. Please cite only the published version.; この論文は出版社版でありません。引用の際に は出版社版をご確認ご利用ください。 


\section{Correlations of Kinetic Parameters in Biomass Pyrolysis with Solid Residue Yield}

\section{and Lignin Content}

Kenji Hashimoto $^{\mathrm{a}, \dagger}$, Isao Hasegawa ${ }^{\mathrm{a}}$, Junichi Hayashi ${ }^{\mathrm{b}}$, Kazuhiro Mae $^{\mathrm{a}}{ }^{*}$

${ }^{a}$ Department of Chemical Engineering, Kyoto University, Kyoto-daigaku Katsura, Nishikyo-ku, Kyoto 615-8510,

Japan

${ }^{\dagger}$ Emeritus Professor

${ }^{b}$ Department of Chemical, Energy and Environmental Engineering, Kansai University, 3-3-35 Yamate-cho,

Suita-shi, Osaka 564-8680, Japan

* Corresponding author

Tel.: +8175383 2668. Fax: +81753832658

E-mail:kaz@cheme.kyoto-u.ac.jp 


\section{ABSTRACT}

A kinetic analysis of the pyrolysis of various types of biomass (trunk, bark, leaf, shell, herbage, food dregs, and polysaccharide) as well as synthetic biomass consisting of cellulose and lignin was performed using thermogravimetric analysis data. The reaction rates of biomass pyrolysis were found to be expressed simply by a single nth-order reaction model. The kinetic parameters (frequency factor $\mathrm{k}_{0}$, activation energy $\mathrm{E}$, and reaction order $n$ ) were estimated first by differentiating the thermogravimetric curves and then by the nonlinear estimation method. The rate parameters of the pyrolysis of both 38 biomass samples and 9 synthetic biomass samples were successfully correlated in terms of the solid residue yield $\omega$; charts are presented showing the correlations. Furthermore, a linear correlation was found between $\omega$ and the lignin content $\mathrm{L}$ in the woody biomass. This allows the kinetic parameters of biomass pyrolysis to be estimated using the value of $\omega$, which is obtained from thermogravimetric measurements or estimated from the value of $\mathrm{L}$ for the biomass feedstock. 


\section{Introduction}

Biomass is a renewable resource with great potential as an alternative to fossil fuels for supplying energy. To convert biomass into a convenient and effective fuel, three different conversion processes have been developed: liquefaction, gasification, and pyrolysis. One of the significant problems associated with these processes is how to reduce the bulk volume of biomass feedstock so that it can be transported at a low cost. One promising solution to this problem entails the pyrolysis of woody biomass into char at a location close to the woods where the biomass is gathered, after which the char can be used as a solid fuel or carbon material. A key step in this biomass pyrolysis is the design and operation of efficient reactors that are based on quantitative knowledge of the reaction kinetics of pyrolysis.

A kinetic analysis of biomass pyrolysis is usually conducted using either a thermogravimetric (TG) curve or a differential thermogravimetric (DTG) curve measured with a thermogravimetric analyzer. Burnham and Braun [1] have provided an extensive review of the methods for analyzing the pyrolysis of various types of solid materials, including biomass. Conesa et al. [2] commented on the problems of kinetic models and the experimental techniques used in material decomposition.

Biomass pyrolysis generally consists of complicated multiple reactions, and it is not easy to determine the reaction mechanism in the detail necessary to formulate the reaction kinetics. Thus, several simplified models have been suggested. One simplified kinetic model for biomass pyrolysis involves lumping the complicated multiple reactions together as a single first-order or nth-order reaction, and several methods for estimating the kinetic parameters in these models have been presented [3]. The main pseudo-components in biomass are considered to be cellulose, hemicellulose, and lignin. The pyrolysis rates of these three components are usually expressed in 
terms of the first-order kinetics [4-6]. However, the reaction order of the lignin component has been shown to be somewhat higher than first order $[7,8]$. The single-reaction models for these various components are combined to produce multiple-reaction systems consisting of several parallel reactions, consecutive reactions, or consecutive-parallel reactions [6]. Models that assume the pyrolysis consisting of three independent parallel reactions with the first-order or the nth-order reactions of these pseudo-components have been applied widely $[4,5,7,8]$. These multiple-reaction models are known to fit the experimental results well. The number of kinetic parameters in these multiple reaction models is, however, several times greater than that in the single-reaction model.

Furthermore, it is possible that the number of parallel reactions will extend to infinity with the reactions consisting of a set of first-order irreversible reactions, each of which has its own activation energy $\mathrm{E}$ and frequency factor $\mathrm{k}_{0}$. This model, known as a distributed activation energy model (DAEM), has been used in the analysis of the pyrolysis of coal and biomass $[9,10]$. The distribution function $\mathrm{f}(\mathrm{E})$ is calculated by differentiating the TG curve. However, it is rather tedious to apply $\mathrm{f}(\mathrm{E})$ in designing a pyrolysis reactor since the function is given in the form of a curve.

Another approach to distributed reactivity models assumes that each first-order reaction rate constant $\mathrm{k}$ under isothermal conditions is represented by the gamma distribution function [11]. Mathematical analysis shows that this multiple reaction can be represented by a single nth-order reaction with the order $n$ being greater than one. This type of simplified model has been applied to the catalytic cracking of heavy oil, but it has not yet been applied to the pyrolysis of biomass. 
Most previous papers on reaction kinetics in biomass pyrolysis have focused on constructing models that fit the thermogravimetric experimental results and on estimating the kinetic parameters in the proposed models. However, the kinetic parameters obtained from this modeling research cannot be applied directly to other new biomass samples, so that separate experiments are necessary to estimate the parameters. From a practical point of view, when conducting kinetic studies into the development of biomass pyrolysis processes and the design of pyrolysis reactors, it is desirable that the pyrolysis rate of biomass is described as simply as possible. Furthermore, where relationships between kinetic parameters and some characteristic properties of biomass are found, we could estimate the pyrolysis rate of the biomass without tedious experimental work.

In this paper, therefore, we show that the rates of biomass pyrolysis can be expressed approximately by single nth-order reaction kinetics and that the rate parameters are correlated with the solid residue yield $\omega$ and the lignin content L of woody biomass. Combining these correlations, we are able to estimate kinetic parameters of the biomass pyrolysis.

\section{Biomass samples and grouping}

\subsection{Biomass samples and pyrolysis conditions}

In this study, we kinetically analyzed the mass loss curves (TG curves) in the pyrolysis of various types of biomass samples. The TG curves used in the kinetic analysis were derived mainly from experimental data acquired at Kyoto University and Kansai University, with the remainder obtained from various published sources. Some data include TG curves measured at multiple heating rates, while other data include the curve for only a single heating rate. We worked with data from 47 types of biomass samples. Details for each data source are as follows: 
$<1>$ Samples at Kyoto University (19 types of biomass) [12]

(1) Synthetic biomass samples: mixtures of cellulose and lignin in various ratios; synthetic biomass (9 types),

(2) Typical biomass: trunk (cypress, cedar, pine, and apricot), rice husks, and palm shells (6 types),

(3) Bark and leaf parts: cypress bark, cedar bark, cypress leaf, and cedar leaf (4 types)

Mass loss in the pyrolysis of these three sample groups was measured with a sensitive thermogravimetric analyzer (Shimadzu TGA-50) at a specific heating rate up to $1173 \mathrm{~K}$ and in a nitrogen flow of $50 \mathrm{~mL} \cdot \mathrm{min}^{-1}$. The initial mass of the samples ranged from 3 to $4 \mathrm{mg}$. The diameters of the biomass samples were maintained at less than 74 $\mu \mathrm{m}$ in order to remove the effects of mass and heat transfer limitations on kinetic parameters. Commercial crystalline cellulose (Avicel) and hardwood sulphite lignin (Nacalai Tesque) were used in the preparation of the synthetic biomass samples. The TG curves for the synthetic biomass and typical biomass were measured at three heating rates $\left(\beta=10,5\right.$, and $\left.2 \mathrm{~K} \cdot \mathrm{min}^{-1}\right)$, and the curves for the bark and leaf parts were measured at a single heating $\operatorname{rate}\left(\beta=10 \mathrm{~K} \cdot \mathrm{min}^{-1}\right)$.

$<2>$ Samples at Kansai University (16 types)

(4) Bark: cedar and cypress (2 types),

(5) Shells: walnut, tamarind, pistachio, almond, peanut hull, and coconut (6 types),

(6) Herbage: bagasse (1 type),

(7) Food dregs: bean curd, yeast-B, beer lees, and bran (4 types),

(8) Polysaccharides: cyclodextrin, xylan, and starch (3 types) 
The experimental apparatus and conditions used to measure the TG curves at Kansai University were similar to those at Kyoto University. The initial mass of these samples ranged from 3 to $5 \mathrm{mg}$, and the diameters of the samples were all less than $500 \mu \mathrm{m}$. The only heating rate employed was $\beta=10 \mathrm{~K} \cdot \mathrm{min}^{-1}$.

$<3>$ Dr Kajitani's samples (5 types) [13]

Cedar chip, cedar chip barks, Douglas fir, rice husks, and bamboo (5 types )

Kajitani's TG curves were measured using a thermogravimetric analyzer (Mac Science). A 5-mg sample was pyrolyzed at a heating rate of $10 \mathrm{~K} \cdot \mathrm{min}^{-1}$ in an argon flow of $450 \mathrm{~mL} \cdot \mathrm{min}^{-1}$, and the average diameter of the samples was about $200 \mu \mathrm{m}$.

$<4>$ Experimental data from several literature sources (7 types)

Xylan [14], hemicellulose [14], olive B [15], forest residue [15], cotton residue [15], pine sawdust [16], and mustard straw and stalk [17] (7 types)

The TG data from these references were measured using accurate microthermal analyzers under the following experimental conditions: sample weight, 5-25 mg; sample size, 70-250 $\mu \mathrm{m}$; heating rate, 5-50 $\mathrm{K} \cdot \mathrm{min}^{-1}$; nitrogen flow rate, $40-300 \mathrm{~mL} \cdot \mathrm{min}^{-1}$; and the maximum temperature of TG measurement, 973-1273 K. These references include clear TG curves of biomass samples measured over sufficiently high temperature ranges and can be evaluated to give the values of the solid residue yield.

As described in this section, we are concerned with thermogravimetric data of biomass samples collected from a wide variety of sources. We confirmed that the TG data were measured over sufficiently high temperature ranges with samples that were sufficiently small in amount and size, using slow heating rates and high flow rates of 
atmospheric gas stream in order to diminish the effects of mass and heat limitation. Thus, all the thermogravimetric data in this paper can be treated uniformly.

\subsection{Grouping of biomass samples}

We worked with data from a wide range of biomass species. These data can be sorted in two ways. First, the experimental data from 15 biomass samples consisting of 9 synthetic biomass and 6 typical biomass samples at Kyoto University have TG curves measured at three different heating rates, while the experimental curves for the 32 remaining biomass samples were measured at a single heating rate. For samples with TG curves measured at several heating rates, it is possible to estimate the kinetic parameters accurately using a two-step calculation procedure that is explained in a later section. Using the TG curves of these biomass samples, we aimed to find relationships between the kinetic parameters and some characteristic value of the biomass samples. We therefore regard these 15 samples as a group of standard biomass samples.

After obtaining these relationships, we mixed samples from several sources together and categorized them according to usual biomass classification: synthetic biomass, trunk, bark, leaf, herbage, food dregs, and polysaccharides. Table 1 lists the data sources and the names of all samples classified according to this second method, and it also includes estimated values of the kinetic parameters and several related characteristic values of biomass. We numbered all the samples serially and denoted the standard biomass samples by a $*$ to distinguish them from the 32 remaining samples.

\section{Stoichiometry of pyrolysis using a thermogravimetric analyzer}


Although biomass pyrolysis is a complicated reaction, it can be represented simply by the following single reaction.

$$
\mathrm{B} \rightarrow \mathrm{s} \mathrm{S}+\mathrm{vV}
$$

where $\mathrm{B}$ is biomass, $\mathrm{S}$ is a solid product (char), $\mathrm{V}$ is volatile matter, and $\mathrm{s}$ and $\mathrm{v}$ are the yield coefficients of the solid product $\mathrm{S}[\mathrm{kg}-\mathrm{S} / \mathrm{kg}-\mathrm{B}]$ and the volatile matters $\mathrm{V}[\mathrm{kg}-\mathrm{V} / \mathrm{kg}-\mathrm{B}]$, respectively.

In this section, we deal with the TG curves represented in terms of the dry and ash-free (daf) basis. The stoichiometry and material balance equations are also expressed on a daf basis. The mass $\mathrm{W}_{\mathrm{t}}$ measured using the thermogravimetric analyzer is the sum of the mass of the unreacted biomass $W_{B}$ and the mass of the solid product $\mathrm{W}_{\mathrm{S}}$, which is equal to the product of the reacted solid mass $\left(\mathrm{W}_{\mathrm{B} 0}-\mathrm{W}_{\mathrm{B}}\right)$ and the stoichiometric coefficient $\mathrm{s} . \mathrm{W}_{\mathrm{B} 0}$ is the solid mass at the start of the reaction. Then, we obtain the following relationship:

$$
\mathrm{W}_{\mathrm{t}}=\mathrm{W}_{\mathrm{B}}+\mathrm{W}_{\mathrm{S}}=\mathrm{W}_{\mathrm{B}}+\left(\mathrm{W}_{\mathrm{B} 0}-\mathrm{W}_{\mathrm{B}}\right) \mathrm{s} .
$$

Dividing both sides of Eq. (2) by $\mathrm{W}_{\mathrm{B} 0}$ and introducing the dimensionless variables $\mathrm{y}_{\mathrm{t}}$ and $\mathrm{z}$ as defined by Eq. (3), we obtain the dimensionless relationship in Eq. (4):

$$
\begin{aligned}
& \mathrm{W}_{\mathrm{t}} / \mathrm{W}_{\mathrm{B} 0}=\mathrm{y}_{\mathrm{t}}, \quad \mathrm{W}_{\mathrm{B}} / \mathrm{W}_{\mathrm{B} 0}=\mathrm{z} . \\
& \mathrm{y}_{\mathrm{t}}=\mathrm{z}+(1-\mathrm{z}) \mathrm{s},
\end{aligned}
$$

where $\mathrm{y}_{\mathrm{t}}$ is the relative mass of the sample in the analyzer and $\mathrm{z}$ is the fraction of unreacted biomass, known as the unreacted conversion. 
When $\mathrm{B}$ is completely consumed, the unreacted conversion $\mathrm{z}$ is equal to 0 , and the following relationship can be derived from Eq. (4),

$$
\mathrm{s}=\omega
$$

where $\omega$ represents the value of $y_{t}$ at $\mathrm{z}=0$ and is called the solid residue yield.

Substituting Eq. (5) into Eq. (4) and solving for z, the unreacted conversion of $z$ is expressed by

$$
\mathrm{z}=\left(\mathrm{y}_{\mathrm{t}}-\omega\right) /(1-\omega)
$$

When the TG data are given on a moisture and ash-containing basis, these data can be transformed into the daf basis using the following equation:

$$
y_{t}=\left(M_{t} / M_{t 0}-a\right) /(1-a)
$$

where $\mathrm{M}_{\mathrm{t}}$ is the dry total mass of the solid reactant and the solid product containing ash, $\mathrm{M}_{\mathrm{t} 0}$ is the initial mass of the sample, and a is the mass fraction of the ash in the original dry sample.

\section{Fundamental equations and methods for estimating kinetic parameters of biomass pyrolysis}

4.1. Rate equation of pyrolysis and equation of material balance

The reaction rate $\mathrm{r}\left[\mathrm{kg} \cdot \mathrm{kg}^{-1} \cdot \mathrm{min}^{-1}\right]$ of the pyrolysis represented by Eq. (1) is regarded as a function of the unreacted conversion $\mathrm{z}$ and the temperature $\mathrm{T}[\mathrm{K}]$ and is assumed to be expressed by the nth-order function given by Eq. (8).

The reaction order $\mathrm{n}$ is not necessarily one but instead is regarded as a parameter to be determined experimentally.

The temperature dependence of the reaction rate is given by an Arrhenius-type equation with a frequency factor $\mathrm{k}_{0}$ and an activation energy $\mathrm{E}$. 


$$
\mathrm{r}=\mathrm{k}_{0} \exp (-\mathrm{E} / \mathrm{RT}) \mathrm{z}^{\mathrm{n}}
$$

The mass balance equation for the biomass $\mathrm{B}$ is given in terms of the unreacted conversion $\mathrm{z}$ and the temperature

T as follows:

$$
-\beta(\mathrm{dz} / \mathrm{dT})=\mathrm{k}_{0} \exp (-\mathrm{E} / \mathrm{RT}) \mathrm{z}^{\mathrm{n}}
$$

where $\beta\left[\mathrm{K} \cdot \mathrm{min}^{-1}\right]$ is the constant heating rate.

Equation (9) can be rewritten in terms of the dependent variable $y_{t}$, which is directly measured in the thermogravimetric experiments, using Eq. (6):

$$
-\beta\left(\mathrm{dy}_{\mathrm{t}} / \mathrm{dT}\right)=\mathrm{k}_{0} \exp (-\mathrm{E} / \mathrm{RT})\left(\mathrm{y}_{\mathrm{t}}-\omega\right)^{\mathrm{n}} /(1-\omega)^{\mathrm{n}-1}
$$

Equation (10) is a separable-variable-type differential equation and can be rearranged into the following equation:

$$
-\int_{1}^{z} \frac{\mathrm{d} z}{z^{n}}=\frac{k_{0}}{\beta} \int_{T_{0}}^{T} e^{-E / R T} \mathrm{~d} T .
$$

The definite integral of the left side is denoted by G(z), and the analytical solutions for $n=1$ and $n \neq 1$ are given by Eqs. (12-a) and (12-b), respectively.

$$
\begin{gathered}
n=1: \quad \mathrm{G}(\mathrm{z})=-\ln \mathrm{z} . \\
\mathrm{n} \neq 1: \quad \mathrm{G}(\mathrm{z})=\left(1-\mathrm{z}^{1-\mathrm{n}}\right) /(1-\mathrm{n}) .
\end{gathered}
$$

On the other hand, the definite integral of the right side of Eq. (11) can be approximated [3,9]. Combining both integrated equations, we obtain Eq. (13), which approximately expresses the relationship between the temperature T and the unreacted conversion $\mathrm{z}$ for the nth-order reaction kinetics. 


$$
\frac{\beta}{T^{2}}=\frac{k_{0} R}{E G(z)} e^{-E / R T}
$$

4.2. Estimating method for kinetic parameters by graphical differentiation

When the TG curves are measured at a number of heating rates (three or more), the kinetic parameters $\mathrm{E}, \mathrm{k}_{0}$, and $\mathrm{n}$ can be estimated by means of the slope of the straight line tangent to the TG curve at the fixed unreacted conversion z. We call this method a graphical differentiation method because the calculation procedure involves the differentiation of the TG curve. We applied the graphical differentiation method to 15 samples: the standard biomass samples in Section 2, the 9 synthetic biomass samples, and the 6 typical biomass samples of trunk, rice husks, and palm shell.

4.2.1. Transformation of the experimental mass loss curve

The experimental mass loss curves ( $\mathrm{y}_{\mathrm{t}}$ versus $\mathrm{T}[\mathrm{K}]$ ) are transformed into plots of the unreacted conversion $\mathrm{z}$ versus $T[K]$ using Eq. (6) with the measured value of $\omega$. In those TG curves where $y_{t}$ decreases gradually with increasing temperature and does not approach a definite value at the final temperature in the experiments, the value of $\mathrm{y}_{\mathrm{t}}$ at the final temperature $(1173 \mathrm{~K})$ of the TG curve is approximated as $\omega$.

\subsubsection{Calculating the activation energy $\mathrm{E}$}

Taking logarithms of both sides of Eq. (13), we can derive the following relationship:

$$
\begin{aligned}
& \ln \left(\beta / T^{2}\right)=\left[\ln \left(\mathrm{k}_{0} \mathrm{R} / \mathrm{E}\right)-\ln \mathrm{G}(\mathrm{z})\right]-(\mathrm{E} / \mathrm{R}) \cdot(1 / \mathrm{T})=\mathrm{b}-\mathrm{ax}, \\
& \mathrm{a}=\mathrm{E} / \mathrm{R}, \quad \mathrm{b}=\ln \left(\mathrm{k}_{0} \mathrm{R} / \mathrm{E}\right)-\ln \mathrm{G}(\mathrm{z}) .
\end{aligned}
$$


According to Eq. (14-a), the plot of $\ln \left(\beta / \mathrm{T}^{2}\right)$ against $1 / \mathrm{T}$ is a straight line with a slope of $\mathrm{E} / \mathrm{R}, \mathrm{R}$ being the gas constant, where both quantities are calculated using the TG curves of the various heating rates (e.g., $\beta=10,5$, and $2 \mathrm{~K} \cdot \mathrm{min}^{-1}$ ) at a specified $\mathrm{z}($ e.g., $\mathrm{z}=0.7)$. We can easily calculate the value of the activation energy $\mathrm{E}$ from the above plot. This approach for evaluating the activation energy has been widely applied [3,9]. The calculation procedure is repeated for other values of $\mathrm{z}(\mathrm{z}=0.5,0.4$, and 0.3$)$ to examine the variation in the value of $\mathrm{E}$ at different levels of unreacted conversion. The variation in the $\mathrm{E}$ value was found to be not significant in most of our experiments. This fact suggests that the biomass pyrolysis can be expressed approximately in terms of a single rate equation, with the arithmetic mean value of $\mathrm{E}$ regarded as a representative value of the activation energy in the nth-order kinetic rate expression.

\subsubsection{Calculating reaction order $\mathrm{n}$ and frequency factor $\mathrm{k}_{0}$}

The activation energy $\mathrm{E}$ has already been determined. After dividing both sides of Eq. (9) by exp(-E/RT), we let the left side equal Y and take logarithms of both sides to give the following equation:

$$
\begin{aligned}
& \ln Y=\ln k_{0}+n \cdot \operatorname{lnz}, \\
& Y=[-\beta(d z / d T)] / \exp (-E / R T)
\end{aligned}
$$

Plots of $\ln Y$ against $\operatorname{lnz}$ for a given value of $\beta$ give a straight line with a slope of $n$ and an intercept of $\operatorname{lnk}_{0}$. By repeating this calculation for other heating rates, we obtain the average kinetic parameters, the reaction order $n$, and the frequency factor $\mathrm{k}_{0}$. The numerical value of $-\mathrm{dz} / \mathrm{dT}$ is obtained by graphically differentiating the TG curve. Since it is not easy to draw the tangent line directly on the TG curve, we first draw the normal lines to the TG 
curves at $\mathrm{z}=0.7,0.5,0.4$, and 0.3 using a small mirror, and then the tangent lines are drawn to intercept the curve perpendicular to the normal line.

In this way, the values of the kinetic parameters $\mathrm{E}, \mathrm{n}$, and $\mathrm{k}_{0}$ of the nth-order reaction rate equation are estimated via the graphical differentiation method. We also use these values as the starting values of the parameters of the iterative estimation in the following nonlinear least squares method.

\subsection{Estimation of parameters by the nonlinear least squares method}

The second step in estimating the parameters is to obtain more accurate values for the kinetic parameters by using the nonlinear least squares estimation (NLE) method. For a given set of parameters, Eq. (10) may be numerically integrated to give the TG curve in terms of $y_{\text {tcal. }}$ Then, the sum of squares of the residuals (SSR) between the experimental and corresponding calculated $\mathrm{y}_{t, e x p}$, as defined by Eq. (16), is computed. The goal of the NLE method is to find the parameter values for which the SSR has a minimum value. We used the method presented by Marquardt. The actual calculation was performed using a software program supplied by the Omega Simulation Co., Ltd.

$$
\mathrm{SSR}=\Sigma\left(\mathrm{y}_{\mathrm{t}, \mathrm{cal}}-\mathrm{y}_{\mathrm{t}, \mathrm{exp}}\right)^{2}
$$

In this problem, fundamental equations containing unknown parameters are given by a nonlinear differential equation. The program provides a numerical solution of the differential equations and NLE. In practical optimization calculations, it is important to assign appropriate starting values to the unknown parameters. If the starting parameter values are set inappropriately, the iteration will not necessarily converge at optimal parameter values. We use suitable starting parameter values already estimated via the differentiation method. Since the 
frequency factor $\mathrm{k}_{0}$ fluctuated considerably, the study was conducted over a wide range — from one hundredth to a hundred times the initial value.

To demonstrate the fitness of the TG curve calculated using the estimated parameters, a fitness index FI [\%] defined by Eq. (17) is introduced [8] to the measured TG curve, where $\mathrm{N}$ is the total number of data in the TG curve. This index is the ratio of the mean value of the residuals between the experimental and corresponding calculated value of the TG curve to the maximum residual value of 1.0, expressed as a percentage:

$$
\text { Fitness index }(\mathrm{FI})=\sqrt{ }(\mathrm{SSR} / \mathrm{N}) \times 100[\%]
$$

\section{4 Demonstration of the two-step estimation method - the case of the cypress trunk sample}

A two-step method combining the graphical differentiation method and the NLE method can be applied to 15 samples, classified as the standard biomass samples described in Section 2. The actual procedure of the two-step estimation method can be simply demonstrated using the case of the cypress trunk sample.

The values of the kinetic parameters estimated by the graphical differentiation method were $\mathrm{E}=1.554 \times 10^{5}$ $\mathrm{J} \cdot \mathrm{mol}^{-1}, \mathrm{n}=1.795$, and $\mathrm{k}_{0}=3.551 \times 10^{12} \mathrm{~min}^{-1}$ for the cypress trunk sample. We substituted these values into Eq. (10) and used the NLE method to obtain more accurate values: $\mathrm{E}=1.512 \times 10^{5} \mathrm{~J} \cdot \mathrm{mol}^{-1}, \mathrm{n}=2.889, \mathrm{k}_{0}=3.531 \times$ $10^{12} \mathrm{~min}^{-1}$. The number of calculations to convergence in the NLE method was 23 . The sum of squared residues (SSR) and the fitness index (FI) were 0.2072 and $5.36 \%$ for the graphical differentiation method, while 0.06039 and $2.88 \%$ for the NLE method.

Comparing the values obtained by the two methods, we can see that the differences in $\mathrm{k}_{0}$ and $\mathrm{E}$ are not large; however, the difference in the reaction order $\mathrm{n}$ is somewhat large. The SSR and the FI was markedly improved by 
the NLE method. Estimation results similar to those from the cypress trunk sample were obtained with other samples in the standard biomass group.

We calculated TG curves using the parameter values obtained by the graphical differentiation method and by the NLE method, and we compared these curves with the measured TG curve. We found that both calculated curves followed the general behavior of the measured curve and that the TG curve estimated with the NLE method agreed more closely with the measured curve than did the curve based on the graphical differentiation method. These findings suggest that the two-step method is efficient when the parameters are first estimated using the graphical differentiation method; these estimated parameters are therefore used as the starting values in the subsequent NLE method.

\section{Correlations of kinetic parameters and discussion}

5.1. Preliminary correlation for standard biomass samples - synthetic biomass and typical woody biomass

Finding the relationships between the pyrolysis rate parameters and biomass properties can be useful in the design and operation of pyrolysis processes. We have tried to find such a correlation using the experimental data from the standard biomass samples.

By knowing the chemical composition of the biomass, we can potentially determine its properties of interest. The main components of biomass are cellulose, hemicellulose, and lignin. Therefore, we first selected the lignin content as a candidate for this biomass property. We measured the lignin content as follows. The soluble extractives and the ash were separated from the samples, and the remaining solid material was subjected to a sulfuric acid treatment in order to determine the amount of the insoluble Klason lignin. The remaining part of the 
extractives-free flour, consisting of a mixture of cellulose and hemicellulose, is referred to as the holocellulose. The mass fraction of the insoluble lignin in the mass of the ash and soluble extractives-free sample is defined as the lignin content L [-].

We examined the relationship between the kinetic parameters and the lignin content $\mathrm{L}$ for the standard biomass samples. We found, however, that the correlation for the synthetic biomass samples and that for typical woody biomass samples do not match.

We then examined the relationships between the rate parameters and the solid residue yield $\omega$. One reason for choosing $\omega$ as a characteristic value representing the biomass property is as follows. When TG curves in two experimental runs overlap each other, their kinetic parameters should be equal. One of the representative values of a TG curve is $y_{t}$ at the final temperature in the thermogravimetric analyzer, namely $\omega$. When the $\omega$ value of one experimental run equals to that of another, the TG curves of both runs agree with one another, at least over the range of higher temperatures, and the kinetic parameters of both runs are close to each other. This suggests the possibility that the kinetic parameters are correlated in terms of the $\omega$ value.

By plotting each of the kinetic parameters $\ln \mathrm{k}_{0}, \ln \mathrm{E}$, and $\mathrm{n}$ against $\omega$, we found that each parameter was correlated by means of each of the solid curves shown in Figs. 1(a)-1(c) with some scattering, regardless of synthetic biomass or typical woody biomass.

5.2. Perfection of the kinetic parameter correlation charts and discussions on the effects of mineral matters

For the remaining 32 biomass samples except the standard biomass samples, the data for TG curve arise from only a single heating rate; therefore, we cannot apply the differentiation method for estimating the starting values of the 
kinetic parameters. Fortunately, it is possible to estimate the kinetic parameter values by using the correlation curves with the $\omega$ value on the measured TG curve for a single heating rate. Then, by substituting the parameter values obtained from the correlation curves into the starting values for the iteration in the NLE method, we can estimate improved parameter values. We successively added the values of the kinetic parameters for the 32 biomass samples estimated using the correlation curves first, followed by those from the NLE method, to the correlation charts, producing an increasing number of data points and the perfection of the kinetic parameter correlation charts. In this way, we obtained the kinetic parameter correlation charts shown in Figs. 1(a)-1(c), which include the kinetic data from all 47 biomass samples examined in this paper.

To clarify the differences in the charts based on the biomass sample species, we recategorized whole biomass samples into synthetic biomass, trunk, bark, leaf part, shell, herbage, food dregs, and polysaccharides. The values of the kinetic parameters estimated by the NLE method, the solid residue yield $\omega$, and the lignin content L are listed in Table 1 in accordance with the new grouping system. The table also includes the FI value (Eq. (17)) for each sample. These FI values range within $4 \%$, and the average value of FI was found to be $2.41 \%$. This indicates that the TG curves of various biomass samples can be calculated using the rate parameters of the single nth-order kinetics estimated by the method we have presented.

Figures 1(a)-1(c) shows the plot of the kinetic parameters against $\omega$. Although the data in these figures exhibit considerable scatter, there is apparently a correlation between each of the kinetic parameters and $\omega$; it is interesting to note that the correlation curves drawn with the data from the standard samples pass through the middle positions of the scattered data points at the specified value of $\omega$. Since the data points in these figures are classified according to the species of biomass, considering the data points of those species similar to a given sample allows us to 
estimate appropriate values. Thus, Figs. 1(a)-1(c) can be used to estimate the kinetic parameters for biomass pyrolysis.

Actual biomass usually involves several types of mineral matter, some of which have catalytic effects on the pyrolysis rate as well as on the product yields [6-8]. The correlations in Fig. 1 involve the effects of mineral matter, and the scattering of data from the correlation curves is probably caused by the existence of catalytic mineral matter. Possible effects of mineral matter are already reflected in both the TG curve and the value of $\omega$, so the estimated rate parameter values also include such effects. For this reason the correlation charts can be applied regardless of the existence of catalytic mineral matters.

In an actual pyrolysis process, larger pieces of biomass are used, and the effects of the physicochemical conditions will not be the same as those used in the studies described in this paper; therefore, it will probably be necessary to modify the reaction rates based on knowledge from chemical engineering or else measure new TG curves under the conditions of real-world pyrolysis processes.

\subsection{Relationship between $\operatorname{lnk}_{0}$ and $\mathrm{E}$ for all samples; compensation effect}

Comparing Fig. 1(a) with 1(b), we can see that the shapes of the curves are similar and that the frequency factor $\mathrm{k}_{0}$ increases with increasing activation energy E. This means that the decrease in the reaction rate caused by increasing $\mathrm{E}$ is apparently compensated for by an increase in $\mathrm{k}_{0}$. Such a relationship is frequently observed in various chemical reactions $[5,8,9]$ and is called the compensation effect. We found that the relationship between the values of $\operatorname{lnk}_{0}$ and $\mathrm{E}$ listed in Table1 is described by Eq. (18) regardless of whether synthetic biomass or woody biomass is involved. This suggests that pyrolysis reactions of various types of biomass, including synthetic biomass, can be treated similarly. 


$$
\operatorname{lnk}_{0}=2.42 \times 10^{-4} \mathrm{E}-7.04
$$

The average error between the $\operatorname{lnk}_{0}$ values calculated using Eq. (18) and the corresponding values listed in Table 1 was found to be $3.8 \%$.

\subsection{Value of the reaction order $n$}

Figure 1(c) shows that the apparent reaction orders of biomass pyrolysis are much larger than one. Pyrolysis of cellulose and hemicellulose has a first-order reaction rate [4-6], while pyrolysis of lignin is described in terms of higher order kinetics than the first order [7,8]. If a multiple reaction consisting of an infinite number of first-order parallel reactions and reaction rate constants at a certain temperature is described by a gamma function, then this multiple reaction can be expressed by a single nth-order reaction whose order is greater than one [11]. However, it is difficult to explain why the value of $n$ estimated in this paper is so large.

Let us consider why such a high order should be estimated from the measured TG curves. As shown in Table 1, the values of $\mathrm{E}$ range from 150 to $250 \mathrm{~kJ}^{\mathrm{mol}}{ }^{-1}$. The rate constant of reactions with such a high activation energy is small for lower temperatures, and it increases rapidly with increasing temperature. On the other hand, the unreacted conversion $\mathrm{z}$ decreases with an increase in temperature on the TG curve. As shown in Fig. 3, typical biomass pyrolysis proceeds similarly over a temperature range of 500-700 K, while above $700 \mathrm{~K}$ the TG curve declines gradually and almost linearly. Since the pyrolysis rate $\mathrm{r}$ is given as a slope of the TG curve, the rate is considered to be almost constant over a higher temperature range. To satisfy this behavior of the TG curve, the concentration term of the reaction rate $\mathrm{z}^{\mathrm{n}}$ must decrease rapidly so that the effects of temperature - a rapid increase in the reaction rate - are canceled, causing the rates to remain constant. Unreacted conversion $\mathrm{z}$ takes a smaller value than 1 , and hence a larger reaction order $\mathrm{n}$ leads to a rapid decrease in $\mathrm{z}^{\mathrm{n}}$. Consequently, the reaction rate - expressed as the 
product of a term that increases with temperature and one that decreases with concentration - does not noticeably change despite the progression of pyrolysis. Such a tendency becomes more remarkable with increasing activation energy $\mathrm{E}$, and the reaction order $\mathrm{n}$ becomes larger.

\section{Estimation of kinetic parameters using the relationship between solid residue $\omega$ and biomass property}

\subsection{Correlation between solid residue yield $\omega$ and lignin content $\mathrm{L}$}

The value of $\omega$ is necessary to estimate the kinetic parameters from the correlation charts of Figs. 1(a) to 1(c), and TG measurements are required to obtain the value of $\omega$. Thus, when the relationship between $\omega$ and the biomass properties is clarified it can be put to practical use. The main pseudo-components in biomass are cellulose, hemicellulose, and lignin, and the solid yield of cellulose is lower than the yields of the other two components, as listed in Table 1. Therefore, most solid residue is probably formed from lignin and hemicellulose.

Antal et al. [18] demonstrated a correlation between the yield of carbon and the acid-insoluble lignin content of biomass feed. In Fig. 3, $\omega$ is plotted against L for woody biomass containing lignin and cellulose (24 types of biomass) and for the synthetic biomass consisting of lignin and cellulose (7 samples). Pure cellulose and lignin, food dregs, polysaccharides, and other woody biomass without data on L in Table 1 are omitted from Fig. 2.

Although the data in this figure are widely scattered, it can be seen that $\omega$ generally increases with increasing L, and linear regression produces the following line:

$$
\omega=0.284 \mathrm{~L}+0.105
$$

The average error between the $\omega$ values calculated using Eq. (19) and the experimental value was found to be 16.4\%. Careful observation of Fig. 2, however, indicates that the calculated $\omega$ values for biomass of the trunk types 
are higher than the experimental values by about 0.05 at maximum, while the calculated $\omega$ values for biomass of shell types are mostly smaller than the experimental values by about 0.05 at maximum. Data for other samples are almost correlated by Eq. (19). When the type of biomass sample is known, it is possible to adjust the deviation from the correlation line using the actual data in Fig. 2.

The composition of woody biomass is assumed to consist simply of lignin $(\mathrm{L})$ and a mixture $(\mathrm{CH})$ consisting of cellulose $(\mathrm{C})$ and hemicellulose $(\mathrm{H})$. The solid residue yield of lignin and that of the mixture of $\mathrm{C}$ and $\mathrm{H}$ are represented by $\omega_{\mathrm{L}}$ and $\omega_{\mathrm{CH}}$, respectively. If $\omega$ is assumed to be given by the additive contribution rule for the terms $\omega_{\mathrm{L}}$ and $\omega_{\mathrm{CH}}$, the following equation is obtained

$$
\omega=\mathrm{L} \omega_{\mathrm{L}}+(1-\mathrm{L}) \omega_{\mathrm{CH}}=\left(\omega_{\mathrm{L}}-\omega_{\mathrm{CH}}\right) \mathrm{L}+\omega_{\mathrm{CH}} .
$$

Comparing Eq. (19) with Eq. (20), we evaluate the values of $\omega_{\mathrm{L}}$ and $\omega_{\mathrm{CH}}$ as follows: $\omega_{\mathrm{L}}=0.389$ and $\omega_{\mathrm{CH}}=0.105$.

As shown in Table 1, the measured $\omega$ values of $L, C$, and $H$ are $0.424,0.0161$, and 0.283 , respectively. The $\omega$ value of the mixture of $\mathrm{C}$ and $\mathrm{H}$ is likely to be approximated by the arithmetic mean value of 0.016 and 0.283 , or 0.150. Thus, we have $\omega_{\mathrm{L}}=0.424$ and $\omega_{\mathrm{CH}}=0.150$, which almost agree with the previous estimates.

Antal et al. [18] conducted pyrolysis of biomass chips $(3 \times 3 \times 5 \mathrm{~cm})$ in a closed vessel at elevated pressure $(1$ $\mathrm{MPa}$ ) to obtain a high yield of charcoal. They plotted the relationship between the fixed-carbon yield $\mathrm{y}_{\mathrm{fc}}$ and the acid-insoluble lignin content. Although their data were considerably scattered, their correlation line was found to be represented by Eq. (21), as demonstrated by the dotted line in Fig. 3.

$$
\mathrm{y}_{\mathrm{fc}}=0.240 \mathrm{~L}+0.225 \text {. }
$$


We note that $\mathrm{y}_{\mathrm{fc}}$ in the study by Antal et al. and $\omega$ in the present study do not have the same characteristics, and the experimental conditions in the two studies also differed; therefore, we cannot compare the values directly. Nevertheless, it is interesting that the two correlation lines are almost parallel. From Fig. 3, we find that the magnitude of $\mathrm{y}_{\mathrm{fc}}$ is larger than that of $\omega$ by about 0.1 . The experimental conditions in the work by Antal et al. included a large sample size, a closed vessel, and elevated pressure. These conditions were found to enhance the charcoal yield [19] and to enlarge the difference between $\mathrm{y}_{\mathrm{fc}}$ and $\omega$.

\section{Examination of the methods for estimating kinetic parameters using two types of correlations}

As the preceding discussion has shown, the kinetic parameters of biomass pyrolysis can be estimated by two different types of procedure. If the solid residue yield $\omega$ is obtained experimentally, the kinetic parameters (frequency factor $\mathrm{k}_{0}$, activation energy $\mathrm{E}$, and reaction order $\mathrm{n}$ ) in the nth-order reaction kinetics can be estimated from the correlation charts (Figs. 1(a)-1(c)), and thus the TG curve can be calculated using these values. We call this procedure "the $\omega$-correlation method."

If data on the lignin content $L$ of woody biomass samples are available, the solid residue yield $\omega$ can be estimated from Eq. 19 and Fig. 2 without the need for pyrolysis experiments, and the kinetic parameters can then be estimated using Fig. 1. This procedure is referred to as "the L-correlation method." To examine the validity of these two methods for estimating kinetic parameters in the nth-order kinetics, we calculated TG curves using the kinetic parameters obtained by the two methods and compared them with the experimental TG curve in Fig. 3. This figure includes the comparisons for the 8 biomass samples. These samples were selected from among a wide variety of types of woody biomass with differing lignin content $\mathrm{L}$ except for the standard biomass samples. The solid lines in Fig. 3 were calculated using the $\omega$-correlation method, and the dashed lines were calculated using the 
L-correlation method. We found that curves calculated by both methods have the same general behavior as the measured curves and also that the curve calculated with the $\omega$-correlation method agrees closely with the curve calculated with the L-correlation method. Thus, we conclude that both estimating methods for kinetic parameters are efficient.

\section{Conclusions}

(1) Pyrolysis reaction rates for various types of biomass can be expressed approximately by a single nth-order reaction model.

(2) Kinetic parameters and the solid residue yield $\omega$ are correlated; measuring $\omega$ enables the estimation of kinetic parameters from the correlation charts.

(3) A linear relationship exists between the solid residue yield $\omega$ and the lignin content $L$ of woody biomass. The value of $\omega$ can be estimated from the correlation chart using the lignin content $\mathrm{L}$ without the need for pyrolysis experiments. This relationship can be used in the estimation of kinetic parameters by combining the correlation of rate parameters relative to the solid residue yield $\omega$.

\section{Acknowledgment}

The authors acknowledge Dr. Kajitani for supplying detailed data on the TG curves of several biomasses. 


\section{References}

[1] Burnham AK, Braun RL. Global kinetic analysis of complex materials. Energy Fuels 1999;13:1-22.

[2] Conesa JA, Marcilla A, Caballero JA, Font R. Comments on the validity and utility of the different methods for kinetic analysis of thermogravimetric data. J Anal Appl Pyrolysis 2001;58:617-33.

[3] Coats AW, Redfern JP. Kinetic parameters from thermogravimetric data. Nature 1964; 201:68-79.

[4] Orfao JJM, Antunes FJA, Figueiredo JL. Pyrolysis kinetics of lignocellulosic materials - three independent reactions model. Fuel 1999;78:349-58.

[5] Garcia-Perez M, Chaala A, Yang J, Roy C. Co-pyrolysis of sugarcane bagasse with petroleum residue. Part I: thermogravimetric analysis. Fuel 2001;80:1245-58.

[6] Varhegyi G, Antal MJ, Jakab E, Szabo P. Kinetic modeling of biomass pyrolysis. J Anal Appl Pyroylsis 1997;42:73-87.

[7] Caballero JA, Marcilla A, Conesa JA. Thermogravimetric analysis of olive stones with sulphuric acid treatment. J Anal Appl Pyrolysis 1997;44:75-88.

[8] Manya JJ, Velo E, Puigjaner L. Kinetics of biomass pyrolysis: a reformulated three-parallel-reactions model. Ind Eng Chem Res 2003;42:434-41.

[9] Miura K, Maki T. A simple method for estimating $f(E)$ and $\mathrm{k}_{0}(\mathrm{E})$ in the distributed activation energy model. Energy Fuels 1998;12:864-9.

[10] Sonobe T, Worasuwannarak N. Kinetic analyses of biomass pyrolysis using the distributed activation energy model. Fuel 2008;87:414-21. 
[11] Crickmore PJ. Power law models as descriptors of the kinetics of complex systems: Temperature effects.

Canadian J Chem Eng 1989;67:392-6.

[12] Hasegawa I, Kanbara K, Fujita K, Mae K. Effect of the interaction between cellulose and lignin on the biomass pyrolysis. In: Proceedings of energy engineering symposium; 2002, p. 143-6.

[13] Kajitani S, Ichikawa K, Inumaru J. Gasification reactivity of biomass for high-efficiency utilization. In: Proceedings of the 13th annual meeting of Japan Institute of Energy; 2004, p. 196-7.

[14] Raveendran K, Ganesh A, Khilar KC. Pyrolysis characteristics of biomass and biomass components. Fuel 1996;75:987-98.

[15] Kastanaki E, Vamvuka D, Grammelis P, Kakaras E. Thermogravimetric studies of the behavior of lignite-biomass blends during devolatilization. Fuel Process Technol 2002;77-78:159-66.

[16] Biagini E, Lippi F, Petarca L, Tognotti L. Devolatilization rate of biomasses and coal-biomass blends: an experimental investigation. Fuel 2002;81:1041-50.

[17] Maiti S, Purakayastha S, Ghosh B. Thermal characterization of mustard straw and stalk in nitrogen at different heating rates. Fuel 2007;86:1513-8.

[18] Antal MJ, Allen SG, Dai X, Shimizu B, Tam MS, Gronli M. Attainment of the theoretical yield of carbon from biomass. Ind Eng Chem Res 2000;39:4024-31.

[19] Mok WS-L, Antal MJ, Szabo P, Varhegyi G, Zelei B. Formation of charcoal from biomass in a sealed reactor. Ind Eng Chem Res 1992;31:1162-6. 

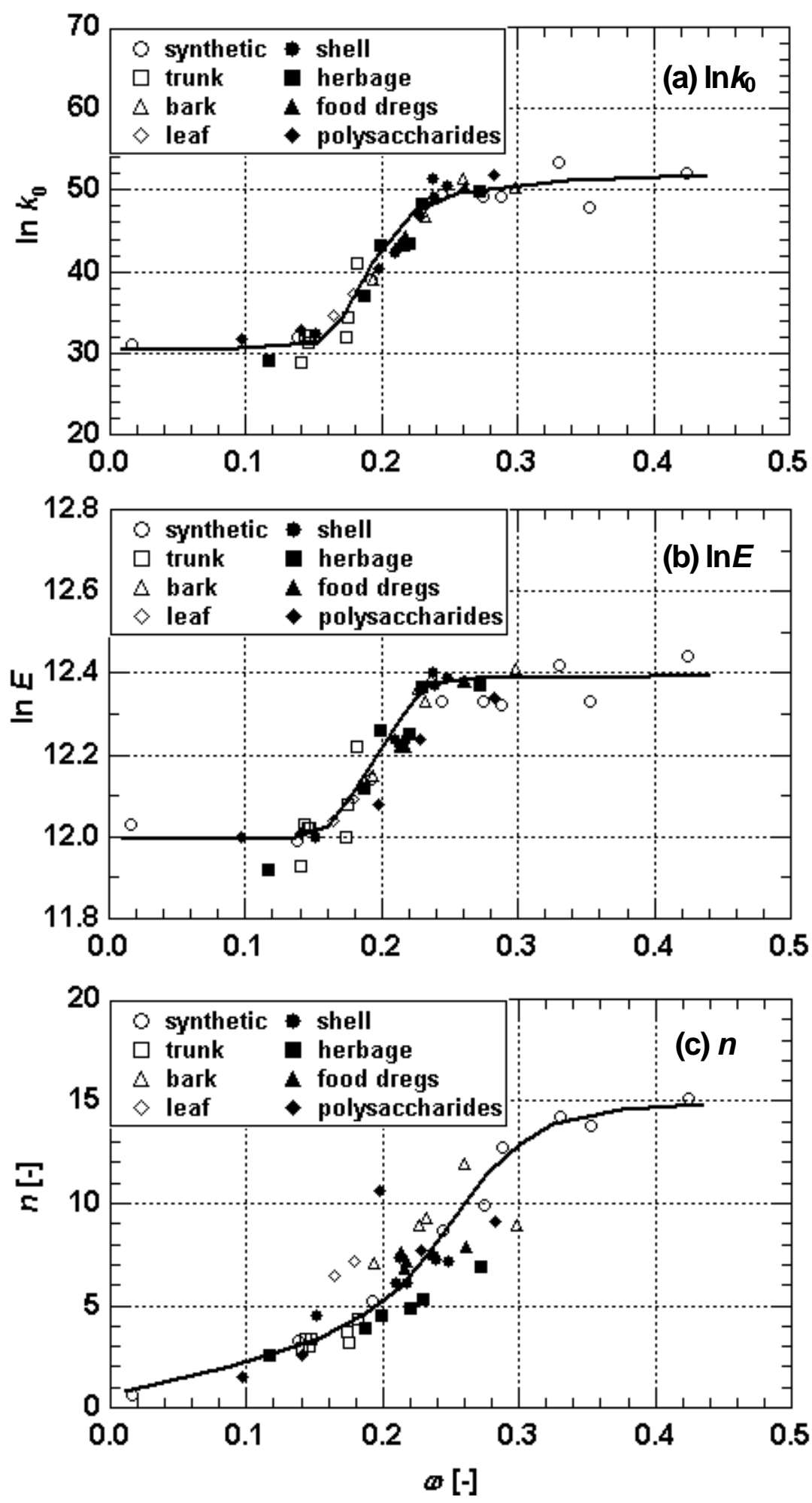

Fig. 1. Correlations of kinetic parameters ( $\operatorname{lnk}_{0}, \operatorname{lnE}$, and $\left.n\right)$ with solid residue yield $\omega$ for all biomass samples 


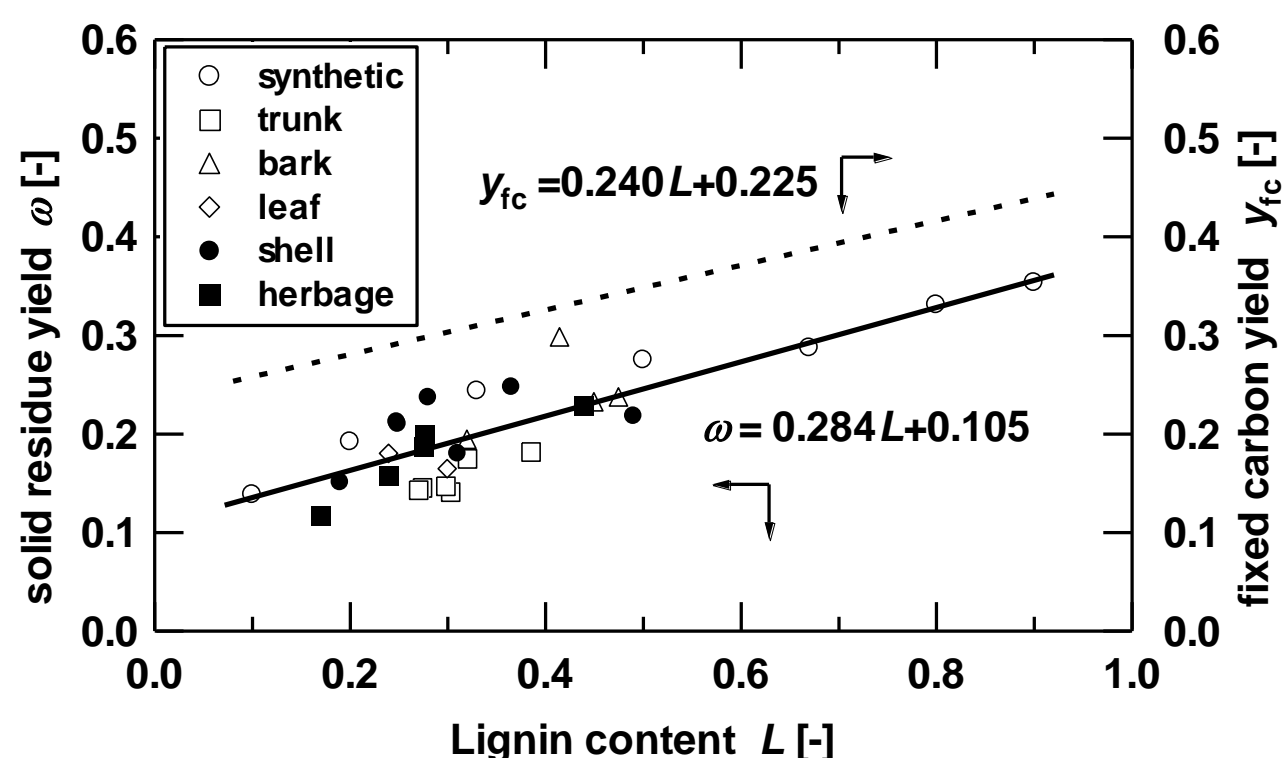

Fig. 2. Relationship between solid residue yield $\omega$ and lignin content $L$ and that between fixed-carbon yield $y_{\mathrm{fc}}$ and $\mathrm{L}$ 

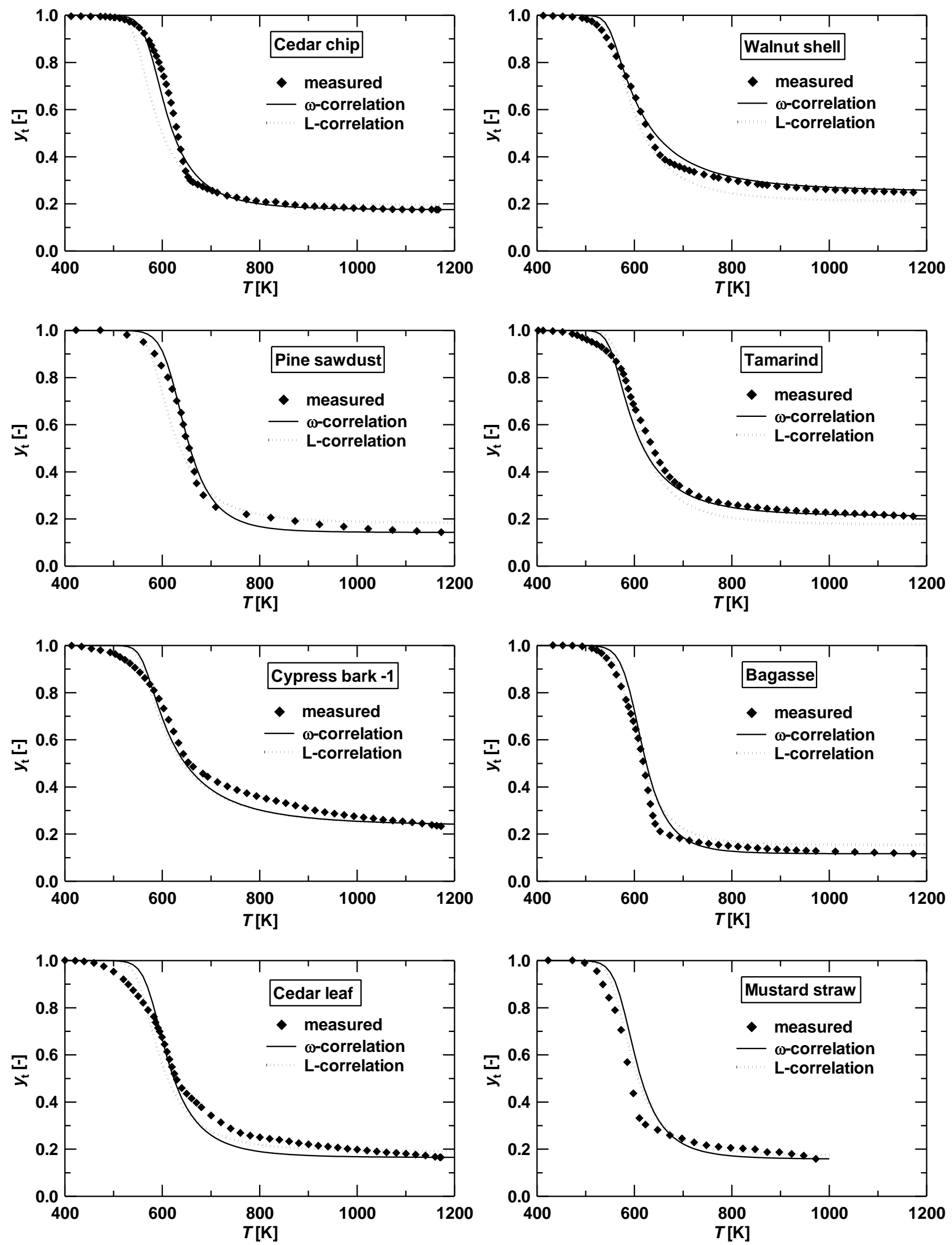

Fig. 3. Comparison between the measured TG curve and two types of calculated TG curves; the solid lines are calculated using rate parameter to $\omega$ correlation ( $\omega$-correlation method); the dashed lines are calculated by combining $\omega$ to L correlation and rate parameter to $\omega$ correlation ( L-correlation method) 
Table 1 Classified biomass samples, their estimated rate parameter values, and the related characteristic values

\begin{tabular}{|c|c|c|c|c|c|c|c|c|}
\hline \multirow[t]{2}{*}{ No } & $\begin{array}{l}\text { Source of } \\
\text { data }\end{array}$ & \multirow[t]{2}{*}{ Sample } & $\mathrm{L}$ & $\omega$ & $\operatorname{lnk}_{0}$ & $\ln E$ & $\mathrm{n}$ & FI \\
\hline & & & {$[-]$} & {$[-]$} & $\mathrm{k}_{0}\left[\min ^{-1}\right]$ & $\mathrm{E}\left[\mathrm{J} \cdot \mathrm{mol}^{-1}\right]$ & {$[-]$} & {$[\%]$} \\
\hline & & Synthetic & & & & & & \\
\hline 1 & Kyoto & $* \mathrm{C} 100$ & 0 & 0.0161 & 31.10 & 12.03 & 0.5824 & 2.18 \\
\hline 2 & Kyoto & ${ }^{*} \mathrm{~L} 10+\mathrm{C} 90$ & 0.1 & 0.1384 & 31.92 & 11.99 & 3.234 & 3.63 \\
\hline 3 & Kyoto & ${ }^{*} \mathrm{~L} 20+\mathrm{C} 80$ & 0.2 & 0.1918 & 38.95 & 12.14 & 5.252 & 3.08 \\
\hline 4 & Kyoto & ${ }^{*} \mathrm{~L} 33+\mathrm{C} 67$ & 0.33 & 0.2435 & 49.37 & 12.33 & 8.642 & 2.76 \\
\hline 5 & Kyoto & ${ }^{*} \mathrm{~L} 50+\mathrm{C} 50$ & 0.5 & 0.2751 & 49.20 & 12.33 & 9.925 & 2.11 \\
\hline 6 & Kyoto & ${ }^{*} \mathrm{~L} 67+\mathrm{C} 33$ & 0.67 & 0.2873 & 49.20 & 12.32 & 12.70 & 2.10 \\
\hline 7 & Kyoto & ${ }^{*} \mathrm{~L} 80+\mathrm{C} 20$ & 0.8 & 0.3309 & 53.40 & 12.42 & 14.25 & 2.24 \\
\hline 8 & Kyoto & ${ }^{*} \mathrm{~L} 90+\mathrm{C} 10$ & 0.9 & 0.3534 & 47.82 & 12.33 & 13.78 & 2.29 \\
\hline 9 & Kyoto & ${ }^{*}$ L100 & 1 & 0.4238 & 52.13 & 12.44 & 15.16 & 2.68 \\
\hline & & Trunk & & & & & & \\
\hline 10 & Kyoto & ${ }^{*}$ Cypress & 0.303 & 0.1409 & 28.89 & 11.93 & 2.889 & 2.88 \\
\hline 11 & Kyoto & *Cedar & 0.385 & 0.1817 & 40.92 & 12.22 & 4.376 & 2.88 \\
\hline 12 & Kyoto & *Pine & 0.274 & 0.1453 & 31.37 & 12.02 & 3.031 & 2.82 \\
\hline 13 & Kyoto & *Apricot & 0.298 & 0.1469 & 32.08 & 12.02 & 3.404 & 2.62 \\
\hline 14 & Kajitani & Cedar chip & 0.320 & 0.1748 & 34.34 & 12.08 & 3.167 & 2.17 \\
\hline 15 & Ref. 15 & Forest residue & - & 0.1743 & 31.90 & 12.00 & 3.702 & 2.30 \\
\hline 16 & Ref. 16 & Pine sawdust & 0.27 & 0.1429 & 32.08 & 12.03 & 3.389 & 2.76 \\
\hline & & Bark & & & & & & \\
\hline 17 & Kyoto & Cypress-1 & 0.45 & 0.2322 & 46.78 & 12.33 & 9.255 & 2.40 \\
\hline 18 & Kyoto & Cedar-1 & 0.32 & 0.1936 & 39.02 & 12.15 & 7.111 & 2.69 \\
\hline 19 & Kansai & Cedar-2 & - & 0.2262 & 47.64 & 12.36 & 8.967 & 2.71 \\
\hline 20 & Kansai & Cypress-2 & - & 0.2593 & 51.33 & 12.38 & 11.91 & 3.12 \\
\hline 21 & Kajitani & Cedar-3 & 0.475 & 0.2374 & 49.15 & 12.39 & 7.491 & 2.54 \\
\hline 22 & Kajitani & Douglas fir & 0.415 & 0.2980 & 50.37 & 12.41 & 8.914 & 2.43 \\
\hline & & Leaf & & & & & & \\
\hline 23 & Kyoto & Cypress & 0.24 & 0.1796 & 37.18 & 12.09 & 7.210 & 2.79 \\
\hline 24 & Kyoto & Cedar & 0.30 & 0.1641 & 34.64 & 12.04 & 6.419 & 2.50 \\
\hline & & Shell & & & & & & \\
\hline 25 & Kyoto & ${ }^{*}$ Palm shell & 0.49 & 0.2178 & 43.12 & 12.24 & 6.132 & 2.13 \\
\hline 26 & Kansai & Walnut shell & 0.365 & 0.2476 & 50.64 & 12.39 & 7.153 & 2.00 \\
\hline 27 & Kansai & Tamarind & 0.249 & 0.2102 & 42.41 & 12.24 & 6.129 & 2.19 \\
\hline 28 & Kansai & Pistachio shell & 0.19 & 0.1507 & 32.32 & 12.00 & 4.487 & 2.29 \\
\hline 29 & Kansai & Almond shell & 0.248 & 0.2123 & 42.96 & 12.23 & 7.351 & 2.19 \\
\hline 30 & Kansai & Peanut hull & 0.31 & 0.1797 & 36.78 & 12.12 & 6.856 & 2.43 \\
\hline 31 & Kansai & Coconut shell & 0.28 & 0.2368 & 51.50 & 12.40 & 7.421 & 1.96 \\
\hline 32 & Ref. 15 & Olive B & - & 0.2215 & 45.84 & 12.31 & 6.826 & 1.79 \\
\hline
\end{tabular}

Herbage 


$\begin{array}{lllllllll}33 & \text { Kyoto } & \text { * Rice husks-1 } & 0.275 & 0.1866 & 37.02 & 12.12 & 3.870 & 2.48 \\ 34 & \text { Kansai } & \text { Bagasse } & 0.17 & 0.1165 & 29.17 & 11.92 & 2.544 & 2.65 \\ 35 & \text { Kajitani } & \text { Bamboo } & 0.276 & 0.1985 & 43.33 & 12.26 & 4.557 & 2.67 \\ 36 & \text { Ref. 17 } & \text { Mustard straw } & 0.240 & 0.1576 & 32.89 & 11.99 & 3.805 & 2.87 \\ 37 & \text { Ref. 15 } & \text { Cotton residue } & - & 0.2199 & 45.39 & 12.28 & 6.414 & 1.64 \\ 38 & \text { Kajitani } & \text { Rice husks-3 } & 0.439 & 0.2291 & 48.26 & 12.37 & 5.299 & 1.88 \\ & & \text { Food dregs } & & & & & & \\ 39 & \text { Kansai } & \text { Bean-curd } & - & 0.2133 & 43.47 & 12.22 & 7.605 & 1.72 \\ 40 & \text { Kansai } & \text { Yeast-B } & - & 0.2610 & 50.32 & 12.38 & 7.910 & 1.14 \\ 41 & \text { Kansai } & \text { Beer lees } & - & 0.2162 & 43.22 & 12.23 & 6.771 & 1.80 \\ 42 & \text { Kansai } & \text { Bran } & - & 0.2177 & 44.23 & 12.22 & 7.204 & 1.83 \\ & & \text { Polysaccharide } & & & & & & \\ 43 & \text { Kansai } & \text { Cyclodextrin } & - & 0.0967 & 31.72 & 12.00 & 1.511 & 2.74 \\ 44 & \text { Kansai } & \text { Xylan-3 } & - & 0.1973 & 40.37 & 12.08 & 10.66 & 3.41 \\ 45 & \text { Kansai } & \text { Starch } & - & 0.1404 & 32.92 & 12.01 & 2.587 & 1.99 \\ 46 & \text { Ref.14 } & \text { Xylan } & - & 0.2285 & 46.72 & 12.24 & 7.731 & 2.43 \\ 47 & \text { Ref.14 } & \text { Hemicellulose } & - & 0.2825 & 51.93 & 12.34 & 9.158 & 2.29\end{array}$

*: standard biomass sample, L: lignin content, $\omega$ : solid residue yield, FI: fitness index, -1: KyotoUniv., -2: Kansai Univ., -3: Kajitani. 